3. European Union. Sixth General Report on the activities of The European Agency for the Evaluation of Medicinal Products 2000. London: European Medicines Agency; 2000. [citado el 25 de marzo del 2011]. Disponible en: http://www. emea.europa.eu/docs/en_GB/document_library/Annual_ report/2009/12/WC500016768.pdf

4. Derr N. Good Guidance Practices. CDER Forum for International Drug Regulatory Authorities, April 20-24, 2009. Silver Spring, MD: US FDA; 2009 [citado el 25 de marzo del 2011]. Disponible en: http://www.fda.gov/downloads/Drugs/ NewsEvents/UCM182502.pdf

5. US FDA. Guidance Drug Safety Information-FDA's Communication to the Public. Silver Spring, MD: US FDA; 2007 [citado el 25 de marzo del 2011]. Disponible en http://www. fda.gov/downloads/Drugs/GuidanceComplianceRegulatoryInformation/Guidances/ucm072281.pdf

6. Gerald Dal Pan. Regulation on pharmacoepidemiology: challenges. 26th International Conference on Pharmacoepidemiology. Brighton, United Kingdom. International Society for Pharmacoepidemiology. August 18, 2010.

Correspondencia: Hans Vásquez Soplopuco

Dirección de Medicamentos, Insumos y Drogas. Ministerio de

Salud. Lima, Perú.

Dirección: Calle Coronel Odriozola 111, Lima 27, Perú.

Teléfono: (511) 422-9200 anexo 403

Correo electrónico: hvasquez@digemid.minsa.gob.pe

\section{SITUACIÓN DE LA SALUD EN EL PERÚ: LA AGENDA PENDIENTE}

\author{
HEALTH SITUATION IN PERU: \\ THE PENDING AGENDA
}

\author{
Ciro Maguiñaa ${ }^{1, a}$ Edén Galán-Rodas ${ }^{2, b}$
}

Sr. Editor. El informe de la Agenda de Salud para las Américas 2008-2017, señaló de manera concluyente: "La exclusión en salud en la Región aparece estrechamente vinculada con la pobreza, la marginalidad, la discriminación (cultural, racial, social y de género) y la estigmatización que sufren los enfermos mentales y las personas con necesidades especiales. El idioma, el empleo en el sector informal, el desempleo y subempleo, el aislamiento geográfico, el bajo nivel de escolaridad y la reducida información sobre los sistemas de salud, son factores importantes para la exclusión en salud“ (1).

\footnotetext{
Decano Nacional del Colegio Médico del Perú. Lima, Perú.

Comité del Médico Joven, Colegio Médico del Perú. Lima, Perú.

Médico Infectólogo - Dermatólogo; b Médico Cirujano
}

Recibido: 23-08-11 Aprobado: 14-09-11
El Perú ha experimentado un importante desarrollo económico, sin embargo, todavía persisten brechas en distintos sectores de la sociedad, que generan injusticias e inequidades. Ejemplo de ello es que cerca del $30 \%$ de la población no tiene acceso a agua potable. El Estado Peruano invierte menos del $2 \%$ del PBI en salud, siendo uno de los presupuestos más bajos en Sudamérica. Tenemos altas tasas de mortalidad materna; mientras que en Lima muere una mujer por causas relacionadas con su embarazo, parto o puerperio; ocho fallecen en Cajamarca, principalmente en las zonas rurales donde está concentrada la pobreza, altas tasas de mortalidad infantil y elevada prevalencia de malaria, dengue, Leishmaniosis y hepatitis B. Han emergido y reemergido nuevas enfermedades, como la peste neumónica en la región La Libertad (2010) y, últimamente, la enfermedad pulmonar por hantavirus (julio 2011) en la región Loreto (2).

De manera especial nos preocupa la tuberculosis (TBC). Esta ancestral enfermedad nos pone entre los nueve países con mayor incidencia a nivel mundial y segunda en tuberculosis multidrogorresistente en Latinoamérica, constituyéndose en una emergencia sanitaria. Además, tenemos altos índices de desnutrición infantil, incremento de enfermedades crónicas como la diabetes mellitus, hipertensión arterial, enfermedades cardiovasculares, incremento de accidentes y violencia, entre otros. El Ministerio de Salud de Perú (MINSA) ha realizado algunos esfuerzos importantes, como la mejora sostenida de la cobertura de vacunación, acciones integradas de control del cólera, TBC, influenza, etc., pero no es suficiente.

El sistema de salud es segmentado y fragmentado. Cerca del $20 \%$ de la población no tiene ningún tipo de cobertura sanitaria. El seguro social cubre solo al $25 \%$ de la población, especialmente la empleocracia pública y privada; el $5 \%$ tiene seguros privados de salud y el $50 \%$ tiene asistencia sanitaria estatal ${ }^{(3)}$. El sistema de salud posee un insuficiente y limitado aseguramiento en salud. Las diferentes medidas políticas implementadas hace más de una década (Seguro Integral de Salud-SIS y recientemente el Aseguramiento Universal en SaludAUS) son soluciones parciales e incompletas que no van al fondo del problema y, por el contrario en muchos casos, perpetúan la segmentación del sistema. La descentralización de salud no ha resuelto las expectativas de las poblaciones afectadas ya que existe una inadecuada oferta de servicios, ello se evidencia en que de 6074 médicos especialistas registrados en el Perú, el 70 \% (5251) se encuentran laborando en Lima ciudad, Lima provincias y Callao y solo 1823 (30 \%) en otras regiones. La brecha deficitaria se amplía en Loreto, Piura, Puno y Madre de Dios ${ }^{(4)}$, existiendo un déficit de 6398 médicos especialistas, según el estudio realizado por el Colegio Médico del Perú (CMP) ${ }^{(5)}$. 
Un gran reto es atender las necesidades de los jóvenes, quienes representan la quinta parte de la población peruana, con grandes carencias en educación y salud, alta prevalencia de consumo de alcohol y tabaco, precariedad laboral ( $70,7 \%$ trabaja sin contrato), sin ningún tipo de seguro de salud $(74,2 \%)$ y alto índice de migración. Más de la quinta parte de los que emigran cuenta con formación profesional, implicando grandes pérdidas económicas para el país ${ }^{(6)}$.

El desarrollo de investigación científica, postergada por diversos gobiernos, debe ser impulsado a todo nivel en forma real y sostenida. Ningún país ha salido del subdesarrollo sin inversión en investigación científica y tecnológica. El Perú compite, en Latinoamérica, por el último lugar en cuanto al presupuesto que se le asigna a investigación y desarrollo $(0,12 \%$ del PBI).

Según cifras oficiales del MINSA, la ejecución de los proyectos de inversión en salud por los gobiernos regionales es muy bajo, Lambayeque ha ejecutado $65,5 \%$, Huancavelica 38,0 \%, Cajamarca 37,4 \%, La Libertad $23,8 \%$. Incluso, en otros departamentos este porcentaje es menor (Cusco 3,9 \%, Puno 0,1 \% y Ayacucho 1,5\%). Deficiente financiamiento, acceso y disponibilidad de medicamentos e insuficiente atención a poblaciones excluidas y dispersas. Desde hace 42 años el CMP, representante máximo de la orden médica, ha hecho llegar a las autoridades políticas y de salud de los diferentes gobiernos, importantes propuestas de solución a la problemática de salud, algunas de las cuales hoy son leyes vigentes, mientras que otras no fueron tomadas en cuenta.

Antes de concluir, se debe recordar que a mediados de 1800 , el Dr. Rudolph Virchow, médico alemán y gran científico, fundador de la anatomía patológica macro y microscópica, y muy comprometido con la política de su tiempo y de su país, postuló La medicina es una ciencia social, refiriéndose al hecho que las causas de las enfermedades no solo son físicas, sino también sociales y económicas ${ }^{(7)}$. Así, la situación de Salud no está ajena al desarrollo económico de los países; se requiere una auténtica inversión por parte del Estado en los sectores de educación y salud, una reforma sanitaria sustantiva, que promueva la construcción de un sistema nacional de salud descentralizado y participativo más solidario, equitativo, humano e inclusivo que, a su vez, sea capaz de lograr objetivos fundamentales como mejorar la salud de la población (siendo la prioridad la pobre y excluida, especialmente la madre, el niño, el joven y el adulto mayor), responder a las expectativas de las personas y brindar una adecuada y sostenida protección financiera.

\section{Conflictos de interés}

Los autores declaran no tener conflictos de interés en la publicación de la presente carta.

\section{REFERENCIAS BIBLIOGRÁFICAS}

1. Organización Panamericana de la Salud. Agenda de salud para las Américas 2008-2017. Washington, DC: OPS; 2007.

2. Ministerio de Salud del Perú. Comunicado sobre muerte de mujer en lquitos por hanta virus [Internet]. Lima: MINSA; 2011 [citado el 3 de agosto de 2011]. Disponible en: http://www.minsa.gob.pe/portada/prensa/notas_auxiliar. asp?nota $=10475$

3. Instituto Nacional de Estadística e Informática. Condiciones de Vida en el Perú. Lima: INEI; 2011.

4. Zevallos L, Pastor R, Moscoso B. Oferta y demanda de médicos especialistas en los establecimientos de salud del Ministerio de Salud: brechas a nivel nacional, por regiones y tipo de especialidad. Rev Peru Med Exp Salud Publica. 2011;28(2):177-85.

5. Cortez VC, Salazar EL, Pancca EV. Análisis actual y prospectivo de la oferta y demanda de médicos en el Perú 2005-2011. Acta med peruana. 2008;25(1):22-9.

6. Ministerio de Salud. Documento técnico: Análisis de Situación de Salud de las y los Jóvenes. Una mirada al Bono Demográfico. Lima: MINSA; 2011.

7. Sigerist HE. Medicine and Human Welfare. New Haven: Yale University Press; 1941.

Correspondencia: Ciro Maguiña Vargas

Dirección: Av. Malecón Armendáriz N. 791, Lima 18, Perú.

Teléfono: (511) 986-653600

Correo electrónico: ciromv202@hotmail.com 